- This paper describes useful methodology for observing the decontamination of dental instruments in a general dental practice setting.

- The method provides robust information because the participants were directly observed by trained surveyors.

- Comprehensive information was recorded onto machine readable data input forms.

- This is the largest observational study of decontamination practice performed on UK general dental practices.

\title{
A method for surveying instrument decontamination procedures in general dental practice
}

\author{
A. J. Smith, ${ }^{1}$ D. Hurrell, ${ }^{2}$ J. Bagg, ${ }^{3}$ S. McHugh, ${ }^{4}$ H. Mathewson ${ }^{5}$ and M. Henry ${ }^{6}$
}

Objective This paper describes an objective method for assessing the decontamination procedures used for reprocessing dental instruments in primary dental care facilities.

Materials and methods The study population comprised all general dental practitioners in Scotland with an NHS list number. A two-stage process was used to identify which surgeries were to be surveyed, using a proportional stratified random sampling method. First, practices were randomly selected in proportion to the distribution of practices within each of the health boards. Then, if there were more than one dentist within a selected practice, simple random sampling was used to identify a single dentist within the selected practice to be approached. The surgery that the dentist worked from and its associated decontamination facilities were the subject of the survey. A set of data collection forms provided questions designed to investigate compliance with extant guidance documents on decontamination. Specific training for the survey team members was provided during a three day course, to ensure consistency of approach. The data collection forms were piloted in 20 dental surgeries.

Results A methodology was developed, which utilised both staff interviews and direct observation of decontamination processes. Data were collected on a set of 28 standard forms, which could be machine read. Three hundred and seventy-three dentists were selected at random from the dental practitioners list held by Practitioner Services, Scotland. One hundred and eighty-nine practitioners either declined to participate or could not be contacted at the address supplied. One

\footnotetext{
1"Senior Lecturer in Microbiology, Infection Research Group, Level 9, Glasgow Dental Hospital and School, 378 Sauchiehall Street, Glasgow, G2 3JZ; ${ }^{2}$ Decontamination Consultant, HealthCare Science Ltd, Unit 4, Northend Industrial Estate, Burymead Road, Hitchin, SG5 1RT; ${ }^{3}$ Professor of Clinical Microbiology, ${ }^{4}$ Statistician, Infection Research Group, University of Glasgow Dental School, 378 Sauchiehall Street, Glasgow, G2 3JZ; ${ }^{5}$ General Dental Practitioner, 176 St Johns Road, Edinburgh, EH12 8BE; ${ }^{6}$ Consultant Nurse Epidemiologist, Health Protection Scotland, Clifton House, Clifton Place, Glasgow, G3 7LN

${ }^{*}$ Correspondence to: Dr Andrew J. Smith

Email:a.smith@dental.gla.ac.uk
}

Online article number E20

Refereed Paper - accepted 18 April 2006

DOI: $10.1038 /$ bdj.2007.125

${ }^{\circledR}$ British Dental Journal 2007; 202: E20 hundred and eighty-four surgeries were surveyed, data were available for analysis from 179 sites. Data from five sites were rejected because of illegibility (three) and incomplete data (two). Each surgery survey was undertaken by a team of two surveyors, comprising one infection control/decontamination expert and one experienced dental practitioner. The survey team interviewed the dental practitioner and dental nurse, reviewed documentation relevant to the survey, directly observed decontamination practices and recorded the physical layout of the premises.

Conclusion The use of machine readable data collection forms, trained survey staff and direct observation of decontamination protocols provides a workable method for accurate collection of decontamination practice in primary care facilities.

\section{INTRODUCTION}

The emergence in the UK during the 1990s of a new form of Creutzfeldt-Jakob disease (CJD), variant CJD (vCJD), has heightened awareness of the potential for person-to-person transmission of prion diseases via re-usable surgical instruments. ${ }^{1}$ Further anxieties have followed the discovery of prion proteins in extraneural tissues, notably lymphoreticular tissues for $\mathrm{vCJD},{ }^{2}$ and more recently in other tissues. ${ }^{3-5}$ The possibility of transmission via blood transfusion has also increased awareness of the potential for iatrogenic transmission of prions. $^{6}$ The abnormal form of the prion protein, which is probably responsible for causing disease, poses difficulties for decontamination of re-usable medical devices, because of its resistance to normal sterilisation procedures. ${ }^{7}$ For this reason, the prion issue has focused attention on the efficacy of current instrument decontamination procedures, particularly presterilisation cleaning, and the need to ensure that appropriate procedures and quality control measures are in place to reduce the risk of transmission of infectious agents. ${ }^{1}$

Whilst much work has been undertaken in the acute hospital sector in the UK to improve the efficacy of decontamination of medical devices, largely through centralisation of the service, relatively little work has been performed in primary care. 
The quantity of instruments re-processed in general dental practice in Scotland has been estimated to be in excess of 180 million items per annum. ${ }^{8}$ The centralisation of sterilisation processes for this volume of instruments would be logistically difficult and local decontamination of dental instruments is likely to continue for most sites. Under these circumstances, it is important that local decontamination is undertaken in line with current recognised standards. Until recently, there were few reliable data to indicate which procedures are used in general dental practice, or elsewhere in primary care, for the washing, disinfection and sterilisation of re-usable dental instruments. A systematic review of this area of dentistry highlighted the need for high quality research that utilises observational methods, since results from previous studies have relied heavily on postal questionnaires, which provide data of dubious quality. ${ }^{9}$

A recent report ${ }^{10}$ has highlighted key findings of decontamination processes from a survey of 179 dental surgeries. This paper describes in detail the methodology that was developed and used in that survey ${ }^{10}$ for the assessment of procedures used in general dental practices to decontaminate re-usable dental instruments and other medical devices.

\section{METHODS}

\section{Study population and selection of surgeries}

The study population comprised all general dental practitioners in Scotland with an NHS list number. Details of the number of practices and dental practitioners in Scotland offering NHS services were obtained from NHS National Services Scotland, Practitioner Services, previously known as the Dental Practice Division of the Common Services Agency. This list was the basis for randomly selecting practitioners to survey.

A two-stage process was used to identify which surgeries were to be surveyed, using a proportional stratified random sampling method. First, practices were randomly selected in proportion to the distribution of practices within each of the health boards. Then, if there were more than one dentist within a selected practice, simple random sampling was used to identify a single dentist within the selected practice to be approached. The surgery that the dentist worked from and its associated decontamination facilities were the subject of the survey.

\section{Consent to surgery visit}

Prior to approaching practitioners to participate in the survey, a framework for the assessment process was developed following consultation with the Scottish Executive Health Department, the Chief Dental Officer for Scotland and the British Dental Association in Scotland. The support of the Local Dental Committee for each Health Board in Scotland was also obtained. Those practitioners selected were invited to participate on an entirely voluntary basis in the survey. Those who agreed to take part were asked to book no patients into the surgery for the session of the visit. A fee was paid by the Dental Primary Care Audit Scheme to compensate for the loss of earnings during the survey session, thus facilitating participation by the practitioner and dental nurse.

Following agreement, in principle, of the dental surgeon to participate, he or she was contacted by phone by the dental practitioner in the survey team assigned to the surgery.
During this call, the logistics of the visit were described in more detail and an opportunity provided for the selected practitioner to seek further clarification of the process. The project administrator then phoned to arrange a suitable time and date for the visit to the surgery. This was organised at least six weeks in advance, to avoid significant patient cancellations being required. The practitioner was also sent a letter indicating the various items of practice documentation which should be available for inspection by the survey team on the day of the visit.

\section{Survey teams}

Each survey was performed by a team of two individuals. One member was an expert on infection control or decontamination; this group included medical microbiologists, clinical scientists, Authorised Persons (sterilisers) and infection control nurses. The second individual was an experienced general dental practitioner, many of whom were Dental Practice Advisers.

\section{Training of the survey teams}

All survey team members attended a three-day training and assessment course provided by University of Glasgow Dental School and Health Protection Scotland. This course provided detailed information on decontamination procedures and standards and also provided information on specialised issues relevant to the dental environment for the benefit of non-dental members of the survey teams. The training provided an overview of decontamination guidance, designed to ensure a common standard of interpretation. All members of the survey teams undertook a pilot survey prior to commencing actual site visits.

\section{Data collection forms}

The data collection forms provided questions designed to investigate compliance with extant guidance documents on decontamination, particularly the British Dental Association (BDA) Advice Sheet A12, 'Glennie Technical Requirements' ${ }^{1}$ and a number of other technical documents. ${ }^{12-15}$ The data collection forms were designed on Cardiff Teleforms (Verity Inc, 894 Ross Drive, Sunnyvale, CA 94089, USA) to permit automatic data recognition (Fig. 1). The refinement of the data acquisition tool and corresponding guidance notes took place over several months and was informed by 20 pilot visits to dental surgeries. A set of 28 standardised reporting forms, referred to as 'automatic data acquisition documentation for the assessment of decontamination' $\left(\mathrm{AD}^{3}\right)$, was developed to ensure a consistent approach to the data collection. The subject areas covered by each form are summarised in Table 1 .

\section{Survey visit protocol}

The survey team visited the surgery on the pre-arranged date. Each visit was planned to last for three hours, during which time no patients were booked into the participating surgery. The review involved only the surgery normally occupied by the randomly selected dentist and his/her dental nurse. Remaining staff worked as normal in other surgeries within the practice. The dental member of the survey team interviewed the dentist, reviewed practice documentation and completed the relevant data collection forms. The infection control member 


\section{Table 1 Summary of data collected}

\begin{tabular}{|c|c|}
\hline Form & Description \\
\hline Survey administrative information & $\begin{array}{l}\text { Record details of the practitioner, practice and surveyors. These data are stored securely and separately } \\
\text { from the main database }\end{array}$ \\
\hline Practice - summary info & $\begin{array}{l}\text { Provide a summary overview of the practice infrastructure, staffing, clinical service provision and } \\
\text { decontamination procedures }\end{array}$ \\
\hline Management of infection control & Provide details of infection control policies, staff communication and staff training in decontamination \\
\hline Procurement & $\begin{array}{l}\text { Gathers information which describes the methods of procurement and the control over the acquisition } \\
\text { of reusable medical devices }\end{array}$ \\
\hline Environment and workflow & $\begin{array}{l}\text { Gathers information, which describes the facilities available for the decontamination of instruments and } \\
\text { examines the movement of both used and sterilised instruments within the surgery and practice }\end{array}$ \\
\hline Summary of decontamination & Summarises the equipment and chemicals used in the decontamination process \\
\hline Manual cleaning & $\begin{array}{l}\text { Gathers information on the extent to which manual cleaning is employed and how manual cleaning is } \\
\text { carried out }\end{array}$ \\
\hline Automatic washer disinfector & Gathers information concerning automatic washer disinfectors \\
\hline Ultrasonic cleaner & Gathers information concerning ultrasonic cleaners \\
\hline Chemical disinfection & Gathers information about the chemical disinfectants used in the surgery \\
\hline Post cleaning inspection & Collects data about the procedures used for inspecting cleaned instruments prior to their being sterilised \\
\hline Packing and tray assembly & Gathers information about packaging of cleaned devices, before and after sterilisation \\
\hline B\&t benchtop sterilisers & Gathers information about bowl and instrument benchtop sterilisers, including testing \\
\hline Vacuum benchtop sterilisers & Gathers information about vacuum benchtop sterilisers, including testing \\
\hline Hot air sterilisers & Gathers information about hot air (dry heat) sterilisers, including testing \\
\hline Sterilisation process control & $\begin{array}{l}\text { Collects information about the procedures in place to ensure appropriate monitoring and quality control } \\
\text { of sterilisation of instruments used in the surgery }\end{array}$ \\
\hline Storage & Collects information on the storage sites available for sterile and sterilised items \\
\hline Transit - on site & $\begin{array}{l}\text { Collects information on the methods for movement of contaminated and sterilised items both within the } \\
\text { surgery and within the practice }\end{array}$ \\
\hline Transit - off site & $\begin{array}{l}\text { Collects information on the methods for movement of contaminated and sterilised items between the } \\
\text { surgery/practice and an external decontamination facility }\end{array}$ \\
\hline Instruments and devices & Collects information on the types and numbers of instruments in the surgery \\
\hline Staff and health \& safety & $\begin{array}{l}\text { Collects data relating to the measures taken to protect the health and safety of staff undertaking } \\
\text { decontamination and the training received by staff in respect of decontamination }\end{array}$ \\
\hline Dental handpieces & Collects data on dental handpiece purchase, decontamination and servicing \\
\hline Loan equipment & Policies and procedures linked to the borrowing and lending of equipment associated with the surgery \\
\hline Subcontractors and maintenance & $\begin{array}{l}\text { Collects information about contractors employed to carry out maintenance and testing on } \\
\text { decontamination equipment }\end{array}$ \\
\hline Validation and testing of washer disinfectors & Examines the validation studies and periodic testing carried out on an automatic washer disinfector \\
\hline Domiciliary care & Records information linked to decontamination of instruments used for domiciliary visits \\
\hline Reference documents & $\begin{array}{l}\text { Collects information on the availability of reference documents on decontamination to the staff } \\
\text { within the surgery }\end{array}$ \\
\hline Surgery layout & $\begin{array}{l}\text { Collects information on the physical layout of the dental surgery and decontamination areas } \\
\text { being surveyed }\end{array}$ \\
\hline
\end{tabular}


interviewed the dental nurse and directly observed this nurse undertaking decontamination procedures.

\section{Confidentiality}

Anonymity of site and individuals was maintained throughout the study. Each dental practice was assigned a unique reference number. All reference to the dental practice was via this unique reference number, with the exception of correspondence to the dental practice from the project administrator. Such correspondence contained no reference to the unique identifier. Every member of the project team signed a confidentiality agreement not to disclose the identity of the practices involved or any details of the data collected.

\section{Data quality, entry and analysis}

All returned forms were submitted to an initial visual quality check, which ensured compliance with the instructions for

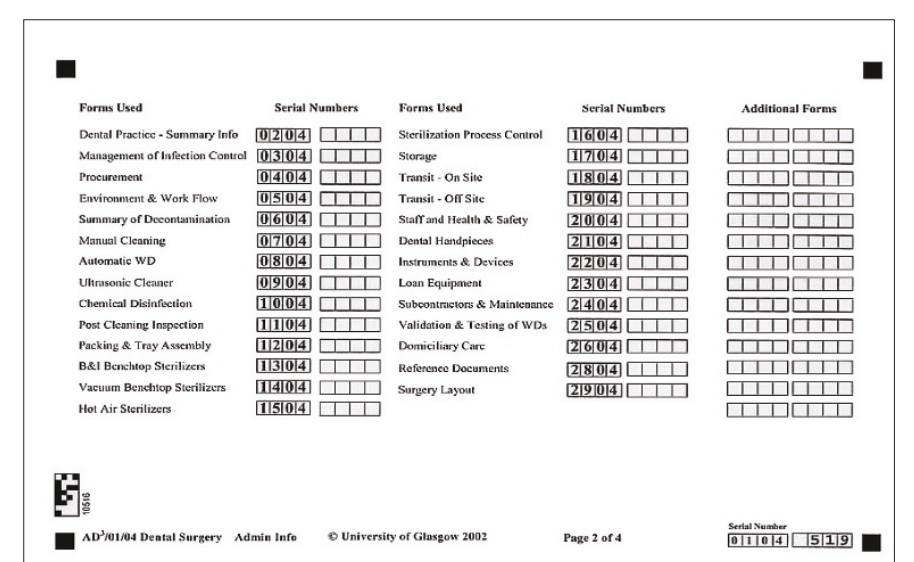

Fig. 1 An example of the automatic data acquisition documentation for the assessment of decontamination $\left(A D^{3}\right)$ forms surveyors contained in the guidance notes. The completed forms were then scanned using an electronic scanner (Panasonic KV SS25U) and downloaded to a database using The Cardiff Teleforms Software Package (Verity Inc, 894 Ross Drive, Sunnyvale, CA 94089, USA). The forms were designed with internal verification, including a serial number on each form, multiple selection boxes, mandatory responses and range values. These checks were run automatically once the forms were scanned. In addition, the responses to a number of critical questions were required to be checked on screen. Forms could be flagged for validation when the verifier was unsure of the surveyor's entry. Once the form had been reviewed, the data were then committed to a Standard Query Language (SQL) Server 2000 database. The practice location information was held separately from the main data to ensure secure data protection. Data were exported from the database into Minitab (version 13) for analysis. Data analysis comprised both tabulated and descriptive statistics.

\section{RESULTS}

\section{Number of practices visited}

Use of this methodology resulted in survey visits to 184 surgeries. This represents approximately $20 \%$ of the total number of general dental practices in Scotland (Table 2). The centrally held dental practice database (NHS National Services Scotland, Practitioner Services) was found to have many inaccuracies. Thus, in order to recruit the 184 surgeries, we attempted to approach 373 randomly selected dentists from the central database. Of these 373 dentists, 40\% were no longer at the practice or the practice itself had closed or moved.

One hundred and eighty-nine practitioners either declined to participate or could not be contacted at the address supplied. Of those who declined, 102 gave reasons for

Table 2 Summary of response rates

\begin{tabular}{|c|c|c|c|c|c|c|}
\hline Health board* & $\begin{array}{l}\text { Number of } \\
\text { practices }\end{array}$ & $\begin{array}{l}\text { Target number of } \\
\text { practices to be } \\
\text { surveyed }\end{array}$ & $\begin{array}{l}\text { Number of } \\
\text { practices selected } \\
\text { to be approached } \\
\text { to participate }\end{array}$ & $\begin{array}{l}\text { Number of } \\
\text { practices } \\
\text { surveyed }\end{array}$ & $\begin{array}{l}\text { Number of } \\
\text { practices with } \\
\text { available data }\end{array}$ & $\begin{array}{l}\% \text { of practices } \\
\text { with available } \\
\text { data }\end{array}$ \\
\hline Argyll \& Clyde & 66 & 17 & 29 & 14 & 14 & 21 \\
\hline Ayrshire \&t Arran & 59 & 15 & 23 & 15 & 15 & 25 \\
\hline Borders & 15 & 4 & 6 & 4 & 4 & 27 \\
\hline Dumfries \&t Galloway & 24 & 6 & 19 & 4 & 4 & 17 \\
\hline Fife & 52 & 13 & 24 & 8 & 8 & 15 \\
\hline Forth Valley & 41 & 11 & 18 & 9 & 6 & 15 \\
\hline Grampian & 56 & 14 & 18 & 14 & 13 & 23 \\
\hline Greater Glasgow & 181 & 46 & 82 & 45 & 45 & 25 \\
\hline Highland & 34 & 9 & 13 & 6 & 6 & 18 \\
\hline Lanarkshire & 76 & 20 & 40 & 15 & 15 & 20 \\
\hline Lothian & 153 & 39 & 67 & 34 & 34 & 22 \\
\hline Orkney & 2 & 1 & 1 & 1 & 1 & 50 \\
\hline Shetland & 3 & 1 & 1 & 1 & 1 & 33 \\
\hline Tayside & 73 & 19 & 31 & 13 & 12 & 16 \\
\hline Western Isles & 2 & 1 & 1 & 1 & 1 & 50 \\
\hline Total & 837 & 215 & 373 & 184 & 179 & 21 \\
\hline
\end{tabular}


non-participation. Twenty-seven percent gave the reason as being a single-handed practitioner, 25\% were too busy and 7\% did not believe that the financial compensation for the surgery downtime was sufficient to cover their costs.

\section{Data processing}

The use of data entry forms specifically designed for dental practice permitted the collection of large amounts of relevant information. The use of a pre-survey training programme and, pilot visits for all surveyors, together with provision of guidance notes for most questions enhanced the consistency of interpretation.

Initial attempts at automated scanning of the data resulted in an error read rate of over 3\%. This level of error was deemed unacceptable and investigation of the scanning parameters and rescanning of data resulted in a scanning error rate of $0.1 \%$.

\section{Data analysis}

From the 184 surgery visits, data were available for analysis from 179 sites. Data from five sites were rejected because of illegibility (three) and incomplete data (two). Each surgery visit generated 1,500 cells of data.

\section{DISCUSSION}

A systematic review of dental staff adherence to infection control guidelines ${ }^{9}$ found that the majority of studies based findings on questionnaire data and the study designs were 'not sufficiently robust to produce reliable findings'. In the small number of studies which have incorporated direct observation, data were recorded using data collection forms not specifically designed for dental practice. ${ }^{16,17}$

Use of the methodology reported here has resulted in the largest survey of decontamination policies and procedures ever reported in primary health care premises..$^{10}$ Furthermore, the ability to directly observe actual decontamination practice and associated policies has produced robust data. These included details on the physical environment, equipment, management processes, knowledge and training undertaken by the dental team. This work has also resulted in the data collection forms being validated as a process assessment tool $\left(\mathrm{AD}^{3}\right)$ for use in general dental practice.

The use of data collection forms, followed by optical scanning, proved a significant obstacle to the timely and accurate transcription of data into an electronic database. The system did not recognise hand written text very well. This increased the amount of time required for data input, as the text often had to be manually entered. Checks (for example, for mandatory responses or ensuring values were within a given range) were run automatically once the forms had been scanned. Forms could be flagged for validation when the verifier was unsure of the surveyor's entry. The time taken for the forms to be reviewed and checked had to be increased before the data were committed to the database. Subsequent work has led to the development of an electronic entry system based on 'Tablet' laptop computers. Data from the laptop can be downloaded directly into the database. We believe that this would be a significant time saver.

Of concern was the accuracy of the central database obtained from NHS National Services Scotland, Practitioner Services, holding information on the location of general dental practitioners in Scotland. If further studies are planned or there is a need for other reasons to contact general dental practitioners in Scotland the inaccuracies of this database will be a major obstacle, a central issue which requires urgent attention.

There were several elements built into the working methods that facilitated the success of this project. A key factor was the close liaison with representatives of the dental profession at all levels. This ranged from the Chief Dental Officer for Scotland, NHS Education for Scotland, the Scottish Branch of the BDA and the various Local Dental Committees and General Practitioner Sub-committees. It also proved invaluable using survey teams that utilised the combined skills of experienced dental practitioners and infection control professionals. We feel that the approach adopted by the survey teams did much to allay initial fears of those practices selected for the survey. The availability of a fee for the practice time whilst not treating patients also played a large part in the acceptability of the study to self employed health care professionals, although a small proportion of practitioners who declined to participate reported that the fee available was not of a sufficient level.

The data collected, which we believe to be very robust, provide a clear indication of how decontamination is currently undertaken in general dental practice. This baseline information is invaluable for informing risk assessments on the potential for onward transmission of infectious agents in primary care and as the basis for action plans to improve decontamination practice. Results of the survey relating to specific aspects of decontamination will be published separately.

In conclusion, we propose a methodology for reviewing decontamination practices in primary care facilities. Whilst costly both in terms of surgery down-time and surveyor time, such an approach leads to the collation of accurate data. In order to provide robust and meaningful information on decontamination policies and procedures in primary care facilities it is imperative that an element of direct observation be employed for future studies on compliance with decontamination technical requirements.

This study was funded by the Scottish Executive Health Department. Additional financial resources were provided by the Chief Dental Officer for Scotland and the Dental Postgraduate Dean at NHS Education for Scotland. We also wish to thank all the surveyors, support staff, practitioners and dental nurses involved in this study.

1. Economics and Operational Research Division, Department of Health. Risk assessment for transmission of $V C J D$ via surgical instruments. London: The Stationery Office; 2001.

2. Hill A F, Butterworth R J, Joiner S et al. Investigation of variant Creutzfeldt-Jakob disease and other human prion diseases with tonsil biopsy samples. Lancet 1999; 353: 183-189.

3. Glatzel M, Abela E, Maissen M, Aguzzi A. Extraneural pathologic prion protein in sporadic Creutzfeldt-Jakob disease. N Engl J Med 2003; 349: 1812-1820.

4. Favereaux A, Perret-Liaudet A, Vital A. Extraneural pathologic prion protein. N Engl J Med 2004; 350: 732-733.

5. Herzog C, Salès N, Etchegaray N et al. Tissue distribution of bovine spongiform encephalopathy agent in primates after intravenous or oral infection. Lancet 2004; 363: 422-428.

6. Llewelyn C A, Hewitt P E, Knight R S G et al. Possible transmission of variant Creutzfeldt-Jakob disease by blood transfusion. Lancet $2004 ; \mathbf{3 6 3}$ : 417-421.

7. Taylor D M. Inactivation of prions by physical and chemical means. J Hosp Infect 1999; 43 (Suppl): S69-S76.

8. NHS Scotland Sterile Services Provision Review Group. $1^{\text {st }}$ Report (The Glennie Framework). Edinburgh: The Stationery Office, 2001. (ISBN 0-7559-0152-5).

9. Gordon B, Burke F, Bagg J, Marlborough H, McHugh E. Systematic review of adherence to infection control guidelines in dentistry. J Dent 2001; 29: 509-516.

10. NHS Scotland Sterile Services Provision Review Group. Survey of decontamination in general dental practice. Edinburgh: The Stationery Office, 2004. (ISBN 0-7559-4362-7). 
11. British Dental Association. Advice Sheet A12. London: BDA, 2003.

12. MHRA. Sterilization, disinfection and cleaning of medical equipment: guidance on decontamination from the microbiology advisory committee to Department of Health. London: The Stationery Office, 2006.

13. NHS Estates (Scotland). Scottish Health Technical Memorandum 2010 (Sterilizers). Edinburgh: The Stationery Office, 2001.

14. NHS Estates (Scotland). Scottish Health Technical Memorandum 2030 (Washer Disinfectors). Edinburgh: The Stationery Office, 1997.
15. Medical Devices Agency. Benchtop steam sterilizers - quidance on purchase, operation and maintenance. Device Bulletin 2002(06). London: The Stationery Office, 2002.

16. NHS Estates (England). Decontamination Review - The report on a survey of current decontamination practices in healthcare premises in England. London: The Stationery Office, 2001.

17. Scottish Health Department Letter (2001)10: Decontamination of medical devices. Edinburgh: The Stationery Office, 2001. 